

\section{DISCLAIMER}

Portions of this document may be illegible in electronic image products. Images are produced from the best available original document. 


\title{
The contact heat conductance at diamond-OFHC copper interface with Galn eutectic as a heat transfer medium
}

\author{
L. Assoufid and A.M. Khounsary \\ Experimental Facilities Division, Advanced Photon Source, Argonne National Laboratory, Argonne, \\ Illinois, 60439, USA
}

(Presented on 19 October 1995)

The results of an experimental study of the contact heat conductance across a single diamond crystal interface with OFHC copper ( $\mathrm{Cu}$ ) are reported. Gallium-indium (GaIn) eutectic was used as an interstitial material. Contact conductance data are important in the design and the prediction of the performance of $\mathrm{x}$-ray diamond monochromators under high-heat-load conditions.

Two sets of experiments were carried out. In one, the copper surface in contact with diamond was polished and then electroless plated with $1 \mu \mathrm{m}$ of nickel, while in the other, the copper contact surface was left as machined.

The measured average interface heat conductances are $44.7 \pm 8 \mathrm{~W} / \mathrm{cm}^{2}-\mathrm{K}$ for nonplated copper and $23.0 \pm 3 \mathrm{~W} / \mathrm{cm}^{2}-\mathrm{K}$ for nickel-plated copper.

For reference, the thermal contact conductances at a copper-copper interface (without diamond) were also measured, and the results are reported.

A typical diamond monochromator, $0.2 \mathrm{~mm}$ thick, will absorb about $44 \mathrm{~W}$ under a standard undulator beam at the Advanced Photon Source. The measured conductance for nickel-plated copper suggests that the temperature drop across the interface of diamond and nickel-plated copper, with a 20 $\mathrm{mm}^{2}$ contact area, will be about $10^{\circ} \mathrm{C}$. Therefore temperature rises are rather modest, and the accuracy of the measured contact conductances presented here are sufficient for design purposes.

\section{INTRODUCTION}

Contact cooling of optical substrates is a common technique for removal of the absorbed x-ray heat from those substrates, and is accomplished by placing cooling pads in contact with the substrate. A thin layer of liquid galliumindium eutectic is often used at the interface to improve the thermal contact and also to provide a strain-free mount for crystal monochromators and mirrors. ${ }^{1-3}$ This technique has been proven to be particularly useful in cooling of diamond monochromators. ${ }^{3}$ Considering the small size of single crystal diamond that can be procured at this time (typically less than $1 \mathrm{~cm}^{2}$ in area), only a small part of which is available for contact cooling, efficient cooling is necessary to avoid high temperature gradients. For design purposes and in order to predict temperature and the performance of a diamond monochromator, it is necessary to know the contact heat conductance at the interface diamond-GaIn-heat sink. A simple experimental setup was devised and used to measure this quantity.

It is well known that liquid gallium, as well as its eutectics, reacts with most metals. ${ }^{4}$ For example, copper, which is very often used as a heat sink, is easily chemically attacked by liquid gallium and its eutectics even at low temperature. To prevent this, copper surfaces are usually plated with a thin layer of nickel. The chemical reaction between nickel and gallium does not occur up to a temperature of about $600^{\circ} \mathrm{C},{ }^{4}$ which is much higher than the operating temperature of a typical monochromator (less $100^{\circ} \mathrm{C}$.
Nickel plating introduces an additional resistance to the heat flow, and, although the thermal conductivity of nickel is relatively poor compared to that of $\mathrm{Cu}(0.91$ versus 3.98 $\mathrm{W} / \mathrm{cm}-\mathrm{K}$ at $300 \mathrm{~K}$ ), the thickness of the plating is too small to make any significant contribution to the temperature drop at the interface. Therefore, the resistance can mainly come from the $\mathrm{Cu}-\mathrm{Ni}$ and $\mathrm{Ni}$-GaIn-diamond interfaces. In order to evaluate the influence of nickel plating, two sets of experiments were carried out. In one, the OFHC Cu surface in contact with diamond was polished and then electroless plated with $1 \mu \mathrm{m}$ of nickel, while, in the other the OFHC Cu surfaces were left as machined.

\section{CONTACT CONDUCTANCE}

It is well known that, at a solid/solid interface, contact occurs at a very few discrete spots, which may result in a large resistance to the heat flow and consequently, a substantial temperature drop at the interface. Contact heat conductance, $h_{c}$, is defined by 5

$$
h_{c}=\left(P / A_{a}\right) / \Delta T,
$$

where $P$ is the total power crossing the interface, $A_{a}$ is the interface apparent contact area, and $\Delta \mathrm{T}$ is the temperature drop across the interface. The experimental setup was to measure this temperature drop. 


\section{A. Parameters influencing the contact conductance}

Thermal resistance (or its reciprocal, the thermal conductance) depends on several geometrical and physical parameters of the contacting solids, including 5 :

a) geometry of the contacting solids: surface roughness and flatness

b) type of interstitial fluid: gas, liquid, grease, vacuum

c) applied interface pressure

d) thermal conductivity of the contacting solids and the interstitial substance

e) hardness of the materials involved.

\section{B. Enhancement of the contact heat conductance}

The heat conductance between two solids can be enhanced by using a variety of interstitial materials, such as soft high-conductivity metal foils, vacuum grease, liquid metals, or by coating one or both surfaces with a soft metal. Further improvement can be obtained by applying a force at the interface.

For synchrotron radiation instrumentation, thermal grease cannot be employed because of the vacuum requirements. Instead, a liquid gallium-indium eutectic is often used. It has a much lower vapor pressure, a better thermal conductivity, and at the same time it can provide a strain-free mounting of $\mathrm{x}$-ray monochromators and mirrors.

\section{EXPERIMENTAL TECHNIQUE/SETUP}

The experimental technique used is similar to the standard technique for measuring the thermal conductivity of solids, which consists of a pair of materials in contact, one with a known thermal conductivity. The assembly is heated at one end and cooled at the other end with a constant temperature cooling fluid. When the steady-state condition is reached, the temperature distribution is measured along both the test pieces with an array of calibrated thermocouples. Then the temperature drop at the interface is calculated, and thus the heat conductance is derived using Eq.1.

However, in the present case, we are dealing with single crystal diamond which are small in size, typically less than 1 $\mathrm{cm}^{2}$ in area and less than $1 \mathrm{~mm}$ in thickness. Therefore, a slightly different arrangement from a typical setup was made, as shown in Figure 1. It consists of two OFHC $\mathrm{Cu}$ rods, $31.8 \mathrm{~mm}$ in diameter and $165 \mathrm{~mm}$ in length, turned down to $6 \mathrm{~mm}$ in diameter over $120 \mathrm{~mm}$ length. The diamond crystal, which has the same diameter as the cooper rods, is then placed between these rods with GaIn eutectic layers at the interfaces. The temperature gradient is measured by 8 equally spaced (20 $\mathrm{mm}$ spacing) miniature K-type thermocouple probes ( $\mathrm{T} 1$ to $\mathrm{T} 8$ ) along the OFHC Cu rods (four in each rod). The thermocouples, each placed in a blind hole drilled into the axis (transverse to the rods) are isolated from each other and from the rods by Teflon holders.

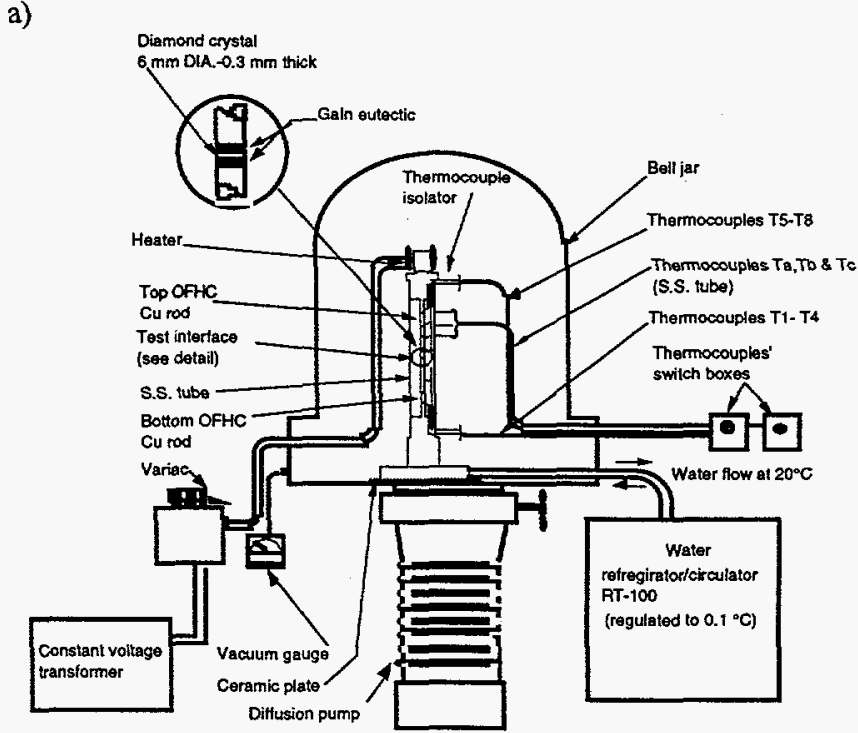

b)

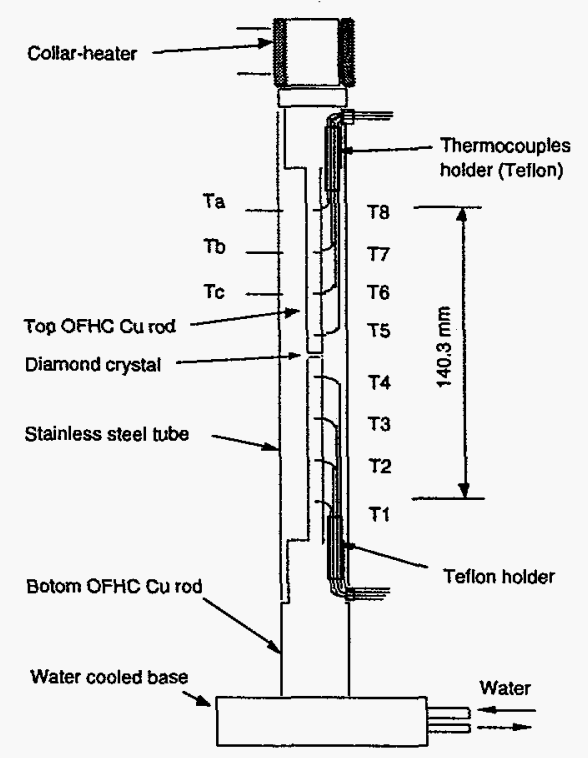

Figure 1.: a) The experimental setup, b) schematic of the experimental device.

Alignment of the rods is maintained by a concentric stainless steel tube. The top rod is heated by an electric heater-collar that can deliver up $100 \mathrm{~W}$. The power is supplied by a constant voltage transformer through a variable voltage transformer. The bottom rod is attached to a water cooled OFHC copper base, and a GaIn layer was used to improve the thermal contact and the stability of the system. The cooling water is maintained at constant temperature $\left(20 \pm 0.1^{\circ} \mathrm{C}\right)$ by a refrigerator/circulator bath. The vacuum system consists of a glass bell jar evacuated by a diffusion pump and a mechanical roughing pump to a pressure less than $10^{-4} \mathrm{Torr}$, which minimizes losses by convection. Temperatures are recorded using a hand-held digital thermometer (model Omega $\mathrm{HH}-23$ ) and two switch boxes. The digital thermometer has a resolution of $0.1^{\circ} \mathrm{C}$. 
In order to evaluate the effect of the nickel plating, two sets of OHFC $\mathrm{Cu}$ rods were made. In one, the tips of the OHFC $\mathrm{Cu}$ rods were polished and then electroless plated with $1 \mu \mathrm{m}$ of nickel, while, in the other, the tips were left as machined. In each case, the heat conductance was evaluated with and without the diamond crystal.

\section{PROCEDURE AND MEASUREMENTS}

\section{A. Thermocouple calibration.}

Before any measurements were performed, all of the thermocouples were checked and calibrated by immersing them all together in a refrigerator/circulator bath (Nestlab model endocal RTEESB). The measurements were made by varying the temperature of the bath from 0 to about $90^{\circ} \mathrm{C}$. The readings of the thermocouples were compared with ASTM certified total immersion thermometers (Brooklyn Thermometers). The thermocouples were found to be identical within $\pm 0.1^{\circ} \mathrm{C}$, which is the same as the resolution of the digital thermometer.

\section{B. Surface characterization and preparation}

The tips of the plated copper rods were polished to a roughness average (RA) of $0.2 \mu \mathrm{m}$ before being electroless plated with $1 \mu \mathrm{m}$ of nickel. The tips of the nonplated copper rods were left as machined with an a roughness average of about $1.6 \mu \mathrm{m}$. The diamond used in this experiment is 6 $\mathrm{mm}$ in diameter and $0.3 \mathrm{~mm}$ thick type IIa crystal purchased from Harris Corporation. ${ }^{6}$ The RMS surface roughness measured by a WYKO profilometer is $0.742 \mu \mathrm{m}$ (RA=0.597).

All the rods were cleaned using acetone and alcohol. The thermocouples were inserted in their respective holes with a layer of conductive grease (Thermalcote ${ }^{\mathrm{TM}}$ from Thermalloy Inc.) in order to ensure the thermal contact. For each test, the surfaces of the tips of the rods were covered with a thin layer of $\mathrm{GaIn}$ eutectic ( $75 \% \mathrm{Ga}$ and $25 \%$ In by mass). Then the rods were put in contact. The thickness of the Galn eutectic is such that it only fills the voids. Therefore the temperature drop due to the bulk conduction is negligible. Note that no attempt was made to study the wetting phenomena for the materials involved. Bare OFHC Cu surfaces are first cleaned from any oxide layer, then they were cleaned with acetone and heated with a heat gun. The wetting of copper by GaIn was then easily obtained by simply rubbing GaIn onto the surfaces. After several hours of operation, GaIn diffuses into $\mathrm{Cu}$ and forms a solid layer, which explains the necessity of plating of copper with nickel.

For the nickel-plated rods, it was observed that, after several runs, a uniform layer forms by simply rubbing GaIn onto the surfaces with a gloved finger. However by looking carefully at the surfaces using a microscope, it was noticed that only a partial wetting was achieved, and, unlike the case of $\mathrm{Cu}$, GaIn does not bond permanently with nickel at low temperature.
The diamond crystal was inserted between the rods without any attempt to wet its surfaces. After several hours of operation, a GaIn film forms on the faces of the diamond. However, it can be easily cleaned using a napkin and acetone. After the rods are put in contact, either with or without diamond in between, the excess of GaIn is removed. The glass bell jar is then closed and evacuated to a pressure less $10^{-4}$ Torr. The steady-state condition is reached after a minimum of 6 hours. However, very often the tests were left for up to 15 hours.

\section{RESULTS AND DISCUSSION}

After the temperature gradients were measured, data are curve fitted using a linear fit. The heat flux is estimated using the thermal conductivity of pure copper ${ }^{7}(3.98 \mathrm{~W} / \mathrm{cm}$ $\mathrm{K}$ at $300 \mathrm{~K}$ ). Then the temperature drop across the interfaces is evaluated for each case by extrapolating the curves. Finally, the heat conductance is derived using Eq. 1.

Figure 2 shows an example of the measured temperature gradient. Table I summarizes the results. Note that, in the experiments involving diamond, the measurements include a double interface. Therefore, the heat conductance for a single face of diamond is calculated by simply using one half of the total measured temperature drop in Eq. 1.

In all cases, the tests were repeated many times to check the reproducibility of the results.

For nonplated OFHC $\mathrm{Cu}$ rods, very little variation was observed. One obtains an average value of about 44.7 $\mathrm{W} / \mathrm{cm}^{2}-\mathrm{K}( \pm 8)$ for the copper-diamond interface and 25.5 $\mathrm{W} / \mathrm{cm}^{2}-\mathrm{K}( \pm 4)$ for the copper-copper interface.

For nickel-plated rods, measured values from 9 to 20 $\mathrm{W} / \mathrm{cm}^{2}-\mathrm{K}$ without diamond, and 16 to $31 \mathrm{~W} / \mathrm{cm}^{2}-\mathrm{K}$ with diamond, were obtained. The variation in the measured numbers reflects simply the differences in the wetting of surfaces by the liquid gallium-indium eutectic.

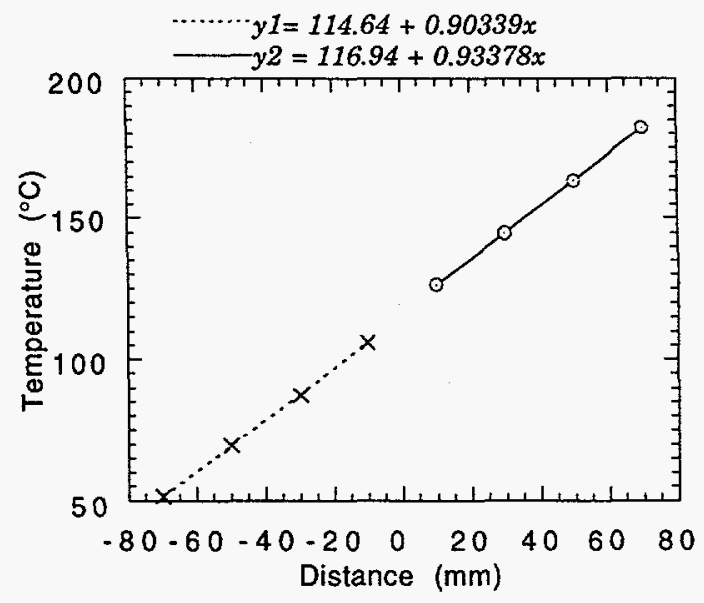

Figure 2. : Example of temperature distribution for nickel-plated copper-diamond interface (run \# 2). Note that the thickness of the diamond crystal $(0.3 \mathrm{~mm})$ is not included in the plot. 
Table I a-b: Results of thermal contact conductance measurements: $q^{\prime \prime}$ is the total heat flux across the interface, $T_{\mathfrak{i}}$ is the estimated temperature at the interface (given for reference only), $\Delta \mathrm{T}_{\text {total }}$ the total temperature drop and heat conductance across all the interfaces, $h_{c}$ is the heat conductance at one single interface $\mathrm{Cu}-\mathrm{GaIn}-\mathrm{Cu}$, or diamond-GaIn- $\mathrm{Cu}$ with or without $1 \mu \mathrm{m}$. nickel plating on the copper rods. Note that, in diamond tests, two interfaces are involved. Therefore, to compute the conductance, $\Delta \mathrm{T}_{\text {total }}$ was simply divided by two in Eq. 1 (see text). The contribution of the thermal conduction in diamond as well as in the GaIn are too small and, therefore, were neglected in the calculations.

Table Ia: Nonplated rods

\begin{tabular}{lccccc}
\hline \hline Experiment & Run $\#$ & $\begin{array}{c}\mathrm{q}^{\prime \prime} \\
\left(\mathrm{W} / \mathrm{cm}^{2}\right)\end{array}$ & $\begin{array}{c}\mathrm{T}_{\mathrm{i}} \\
\left({ }^{\circ} \mathrm{C}\right)\end{array}$ & $\begin{array}{c}\Delta \mathrm{T}_{\text {total }} \\
\left({ }^{\circ} \mathrm{C}\right)\end{array}$ & $\begin{array}{c}\mathrm{h}_{\mathrm{c}} \\
\left(\mathrm{W} / \mathrm{cm}^{2}-\mathrm{K}\right)\end{array}$ \\
\hline Cu-Galn-Cu & 1 & 36.9 & 118.3 & 1.4 & 26 \\
& 2 & 37.0 & 118.5 & 1.5 & 25 \\
Cu-GaIn-diamond & 1 & 23.0 & 76.5 & 1.0 & 46 \\
& 2 & 34.9 & 112.4 & 1.6 & 44 \\
\hline \hline
\end{tabular}

Table Ib: Nickel-plated rods

\begin{tabular}{|c|c|c|c|c|c|c|}
\hline Experiment & Comments & Run \# & $\begin{array}{c}q^{\prime \prime} \\
\left(W / \mathrm{cm}^{2}\right)\end{array}$ & $\begin{array}{c}\mathrm{T}_{\mathrm{i}} \\
\left({ }^{\circ} \mathrm{C}\right) \\
\end{array}$ & $\begin{array}{c}\Delta \mathrm{T}_{\text {total }} \\
\left({ }^{\circ} \mathrm{C}\right)\end{array}$ & $\begin{array}{c}\mathrm{h}_{\mathrm{c}_{2}} \\
\left(\mathrm{~W} / \mathrm{cm}^{2}-\mathrm{K}\right)\end{array}$ \\
\hline \multirow[t]{2}{*}{$\mathrm{Cu}-\mathrm{Ni}-\mathrm{GaIn}-\mathrm{Ni}-\mathrm{Cu}$} & $\begin{array}{l}\text { No mechanical } \\
\text { rubbing of GaIn }\end{array}$ & $\begin{array}{l}1 \\
2 \\
3\end{array}$ & $\begin{array}{l}14.4 \\
28.4 \\
22.8\end{array}$ & $\begin{array}{l}56.0 \\
91.2 \\
81.6\end{array}$ & $\begin{array}{l}1.1 \\
2.3 \\
2.6\end{array}$ & $\begin{array}{c}13 \\
12 \\
9\end{array}$ \\
\hline & $\begin{array}{c}\text { Mechanical } \\
\text { rubbing of GaIn }\end{array}$ & $\begin{array}{l}4 \\
5\end{array}$ & $\begin{array}{l}36.3 \\
35.9\end{array}$ & $\begin{array}{l}117.7 \\
116.3\end{array}$ & $\begin{array}{l}1.8 \\
2.3\end{array}$ & $\begin{array}{l}20 \\
16\end{array}$ \\
\hline \multirow[t]{2}{*}{$\mathrm{Cu}-\mathrm{Ni}$-GaIn-diamond } & $\begin{array}{l}\text { No mechanical } \\
\text { rubbing of GaIn }\end{array}$ & 1 & 29.7 & 95.0 & 3.7 & 16 \\
\hline & $\begin{array}{l}\text { Mechanical } \\
\text { rubbing of GaIn }\end{array}$ & $\begin{array}{l}2 \\
3\end{array}$ & $\begin{array}{l}36.0 \\
35.9\end{array}$ & $\begin{array}{l}116.9 \\
117.2\end{array}$ & $\begin{array}{l}2.3 \\
3.3\end{array}$ & $\begin{array}{l}31 \\
22\end{array}$ \\
\hline
\end{tabular}

In runs \#1-3 for both the $\mathrm{Cu}-\mathrm{Ni}-\mathrm{GaIn}-\mathrm{Ni}-\mathrm{Cu}$ and $\mathrm{Cu}-\mathrm{Ni}$ GaIn-diamond tests, GaIn was simply spread over the surfaces, then the experimental setup was put back together. If the eutectic is applied by simply rubbing it onto the surface with a finger in a glove, the wetting is achieved over the entire nickel-plated area, and contact conductance results are obtained in runs \#4 and 5.

One could conservatively consider the average values and then determine a heat conductance of $14.0 \pm 2 \mathrm{~W} / \mathrm{cm}^{2}-\mathrm{K}$ for $\mathrm{Cu}-\mathrm{Ni}-\mathrm{GaIn}-\mathrm{Ni}-\mathrm{Cu}$, and $23.0 \pm 3 \mathrm{~W} / \mathrm{cm}^{2}-\mathrm{K}$ for $\mathrm{Cu}-\mathrm{Ni}-\mathrm{GaIn}-$ diamond interfaces.

The nickel-plated rods give a slightly larger resistance than non-plated OFHC Cu. This increase is due to $\mathrm{Cu}-\mathrm{Ni}$ and $\mathrm{Cu}$-Ni-diamond interfaces. However, the difference might be largely due to the interface $\mathrm{Ni}$-GaIn-diamond.

Note that, in order to check the variation of the contact heat conductance with the heat load, the measurements were made for various heat fluxes with the same setup. The runs are not all reported because no significant changes were detected. The heat flux was in the range of 14 to $37 \mathrm{~W} / \mathrm{cm}^{2}$.

The heat conductance at the interface of copper-cooper without the GaIn eutectic at the interface, reported in reference 8 , is about $0.17 \mathrm{~W} / \mathrm{cm}^{2}-\mathrm{K}$. This value was measured at a contact pressure of $540 \times 10^{3} \mathrm{~N} / \mathrm{m}^{2}$ or $78 \mathrm{psi}^{8}$ In our case the surfaces were simply put in contact, and the pressure at the interface is less than $100 \times 10^{3} \mathrm{~N} / \mathrm{m}^{2}$. This gives an idea of the improvement that can be obtained by using GaIn eutectic as an interstitial material.

\section{CONCLUSION}

The aim of this work was to provide an estimate of the contact conductance at the interface of diamond and nonplated and $\mathrm{Ni}$-plated $\mathrm{OFHC} \mathrm{Cu}$, with GaIn eutectic at a heat transfer medium. The results presented here will help in predicting the performance of diamond monochromators cooled by contact through a GaIn layer under high-heat-load conditions.

For example, at 7-GeV energy and $100-\mathrm{mA}$ current, a standard undulator at the Advanced Photon Source will deposit $44 \mathrm{~W}$ in a $0.2-\mathrm{mm}$-thick single crystal diamond oriented to diffract $4-\mathrm{keV}$ photons from (111) atomic planes. The measured contact conductance suggests that the temperature drop across the interface of diamond and nickelplated copper, with a $20 \mathrm{~mm}^{2}$ contact area, will be about $10^{\circ} \mathrm{C}$. Therefore temperature rises are rather modest, and the accuracy of contact conductance presented here is sufficient for design purposes.

\section{ACKNOWLEDGMENTS}

We would like to thank Drs. T. Thanh Nhon and R. C. Birtcher for the useful discussion. We are grateful to J. Arko, C. Bresloff, Dr. T. Graber, and M. Jagger for their technical assistance, and to Dr. P. Fernandez for performing the error analysis. 
This work is supported by the U.S. Department of Energy, BES-Materials Sciences, under contract No. W-31-109-ENG-38.

${ }^{1}$ L.E. Berman, J.B. Hastings, D.P. Siddons, M. Koike, V. Stojanoff, and M. Hart, Nuclear Instruments and Methods A239 (1993) 555-563

2 D.H. Bilderback, D.M. Mills, B.W. Batterman and C. Henderson, Nuclear Instruments and Methods A246 (1986) 428-433

$3_{\text {J. Als-Nielsen, A.K. Freund, G. Grübel, J. Linderholm, M. }}$ Nielsen, M. Sanchez del Rio, J.P.F. Shellschop, Nuclear Instruments and Methods B 94 (1994) 306-318

${ }^{4}$ W.D. Wilkinson, Argonne National Laboratory, Report ANL25027, 1953

$5_{\text {M.M. Yavanovich and V.W. Antonetti, Chapter } 2 \text { in Advances }}$ in Thermal Modeling of Electronic Components and System, Volume 1, Edited by A. Bar-Cohen and A D. Kraus, Hemisphere Publishing Corporation, 1988

6 Harris Corporation, 100 Stierli court, Suite 106, Mount Arlington, N.J. 07856, USA.

${ }^{7}$ Y.S. Touloukian, R W. Powell, C.Y. Ho and P. G. Klemens, Thermophysical Properties of Matter, Vols. 2 and 13, IFI/Plenum, New York (1970).

${ }^{8}$ E. Fried and M.J. Kelley, Thermophysics and Temperature Control of Spacecraft and Entry Vehicles, Ed. G.B. Heller, Academic Press, 1966, p697 